\title{
DEFINING THE CRITERIA TO SELECT THE WAVELET TYPE FOR THE ASSESSMENT OF SURFACE QUALITY
}

\author{
Krzysztof Stępień, Wlodzimierz Makiela, Antun Stoić, Ivan Samardžić
}

Preliminary notes

The paper deals with one of the most important problems in the wavelet analysis - the methodology for mother wavelet selection. In this study, the surface texture of machine parts was assessed applying a wavelet transform. The calculations involved in roughness profile evaluation were based on three selection criteria: an autocorrelation test, a cross-correlation function and an entropy-based test. All the calculations and diagrams were produced using the Wavelet toolbox of the MATLAB package.

Keywords: mother wavelet; surface roughness; surface texture; wavelet transform

\section{Definiranje kriterija za izbor tipa valova za procjenu kvalitete površine}

Članak se bavi s jednim od najvažnijih problema u analizi valova - metodologijom izbora matičnog vala. U ovom istraživanju je procjenjena tekstura površine strojnih dijelova uz primjenu transformacije valova. Proračuni uključeni u ocjenu profila hrapavosti su temeljeni na tri kriterija: autokorelacijskom testu, korelacijskoj funkciji i entropijskom testu. Svi proračuni i dijagrami su izrađeni uz korištenje Wavelet toolbox koji je sastavni dio MATLAB programskog paketa.

Ključne riječi: matični val; površinska hrapavopst; pretvorba vala; tekstura površine

\section{Introduction}

The real surface of a machine part is never the same as the ideal theoretical surface, and this may be due to such factors as relative vibrations between the tool and the workpiece or tool wear $[1 \div 3]$. Measuring surface texture of machine parts is essential $[4 \div 6]$, because if there is damage to the surface, there is likelihood of device failure. Different approaches can be adopted to analyse surface texture [7,8]. Some studies focus on determining the influence of the stylus tip [9, 10]. In Ref. [11], the author investigates how the wear of a ceramic tool affects surface roughness in turning. Reference [12] describes an image processing method applied to evaluate surface roughness parameters. In Ref. [13], the authors propose a new approach to surface topography analysis, which is based on empirical surface decomposition. The study presented in [14] considers in-situ roughness measurement using a non-contact profilometer. References $[15 \div 17]$ deal with the latest methods of filtering of surface texture components.

A qualitative analysis, on the other hand, is based on graphical representation of surface irregularities [22 $\div 24]$. Sometimes, additional analysis of the surface texture is required. The most common technique is the Fourier transform, which allows us to detect the predominant harmonic components. The Fourier transform, however, cannot be used to detect local irregularities of a surface profile. In such a case, wavelets and the wavelet transform are applied [25]. Wavelets are small oscillatory wave functions finite in duration. As wavelets are local in time, they are suitable for analysing non-stationary signals They can also be used to detect local irregularities of a surface profile. The wavelet transform is based upon scaling and translation of initial functions called mother wavelets. In practice, there is no criterion to be applied prior to the selection of the mother wavelet. In most cases, the decision is made after visual evaluation of an analysed signal. In this paper, the methodology for mother wavelet selection uses three criteria:

- the autocorrelation of the coefficients of details of the decomposition,

- the cross-correlation function,

- the minimization of the Shannon entropy.

This analysis was performed using the Wavelet Toolbox of the MATLAB package. The signal investigated was a roughness profile of a machine part.

\section{Methods of wavelet \\ 2.1 Pyramid wavelet decomposition}

This method of decomposition involves recursive estimation of sums and differences. Replacing the successive component pairs $x_{i-1}$ and $x_{i}$ of the vector $x$ with their sums $y_{i}$, which are components of the new signal $y$, is equivalent to signal averaging or smoothing. To avoid changing the signal level in this operation, the result is divided by 2 . Eq. (1) describes the simplest low-pass filter:

$y_{i}=\frac{1}{2} x_{i}+\frac{1}{2} x_{i-1}$

Similarly, the equation of a high-pass filter can be written as:

$y_{i}=\frac{1}{2} x_{i}-\frac{1}{2} x_{i-1}$

The algorithm of the pyramid decomposition is shown in Fig. 1. 


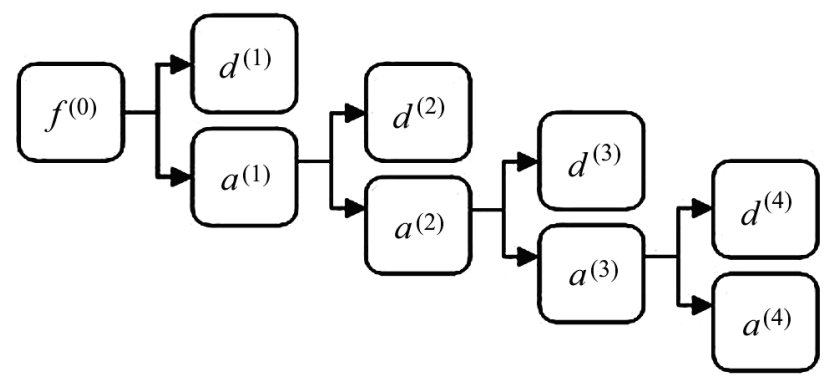

Figure 1 Pyramid wavelet decomposition tree: $f^{(0)}$ - original signal, $a^{(i)}$ - approximation at level $i, d^{(i)}-$ detail at level $i$

\subsection{Wavelet packet decomposition}

Wavelet packet decomposition, which originates from classical wavelet transformation, requires organizing data in a binary tree. A binary tree of decomposition is presented in Fig. 2.

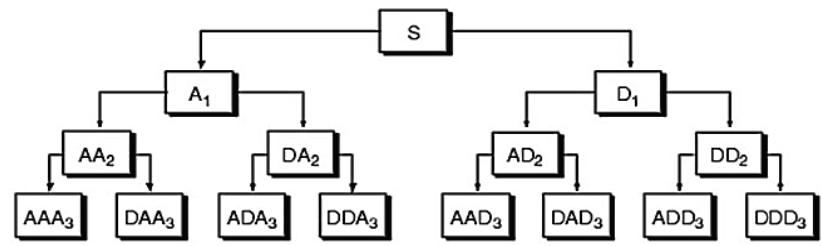

Figure 2 Binary tree of wavelet packet decomposition: $s$ - original signal, $A_{i}-$ approximations at level $i, D_{i}-$ details at level $i$ [26]

At each subsequent level of decomposition, the approximations and details are divided into approximations and details one order higher.

\section{Criteria for selection of mother wavelets \\ 3.1 Autocorrelation}

This test allows us to determine whether the details contain any significant information on the analysed signal or whether the details can be regarded as the white noise. The method assumes that a suitable mother wavelet is selected when there is no significant information about the signal in the detail wavelet coefficients. The fundamentals of the test are Eqs. $(3) \div(5)$, which are used for the calculation of the variance $V$, the covariance $R(k)$ and the test indicator $\chi^{2}$ :

$V=\frac{1}{N} \sum_{i=1}^{N}\left[d_{1}(i)\right]^{2}$,

$R(k)=\frac{1}{N} \sum_{i=1}^{N-k} d_{1}(i) \cdot d_{1}(i+k)$,

$\chi^{2}=\frac{N}{V^{2}} \sum_{k=1}^{m}[R(k)]^{2}$,

where $N$ is the number of the coefficients of the detail $d_{1}$, and $m$ is the natural number from the interval $(5, N / 4)$.

The calculated value of the test indicator $\chi^{2}$ is compared with the predefined critical value using the chisquared distribution for a given confidence level. If the calculated value is higher than the critical value, the hypothesis on good selection of the mother wavelet should be rejected. If the calculated value is lower, the mother wavelet selection is assumed to be correct.

\subsection{Normalized cross-correlation function method}

The normalized cross-correlation function uses the cross-correlation function given by Eq. (6):

$$
r(k)=\frac{2 \sum_{i=1}^{N-k} f(i) \cdot a_{1}(i+k)}{\sum_{i=1}^{N}\left[f^{2}(i)+a_{1}^{2}(i)\right]},
$$

where: $f(i)$ - the coefficients of the original signal, $a_{1}(i)-$ the coefficients of the approximated signals, $k-$ the phase shift between the compared signals.

The higher the maximum of function (6), the better the coincidence between the mother wavelet and the profile irregularities.

\subsection{Entropy-based method}

The entropy-based method is used when wavelet packet decomposition is performed. The method requires determining the maximum of the energy concentration function and an optimal decomposition tree. Since entropy is considered to be the opposite of the energy concentration function, the optimization indicator will be the minimum level of the entropy. The entropy should satisfy the following conditions:

$E(0)=0, E(x)=\sum_{i=1}^{N} E\left(x_{i}\right)$,

where $x_{i}$ is the series of the coefficients of the analysed node.

The calculations performed in the MATLAB environment using the Wavelet Toolbox allow us to determine the following types of entropy:

- the Shannon entropy

$E(x)=-\sum_{i=1}^{N} x_{i}^{2} \cdot \ln \left(x_{i}^{2}\right)$,

- $\quad$ the concentration in $l^{p}$ norm

$E(x)=\sum_{i=1}^{N}\left|x_{i}\right|^{p}, 1 \leq p \leq 2$,

- $\quad$ the logarithm of the "energy" entropy

$E(x)=\sum_{i=1}^{N} \ln \left(x_{i}^{2}\right)$,

where $\ln (0)=0$,

- $\quad$ the threshold entropy 
$E(x)=\sum_{i=1}^{N} E\left(x_{i}\right)$.

An optimal tree is generated by first performing wavelet packet decomposition and then determining the entropy indicator for each node. If the sum of the entropies of two decomposed nodes is higher than the entropy of the input node, then the growth of the decomposition tree should be stopped in this node. If the sum of the entropies is lower, then the decomposition can be continued. In this study, we applied the most common entropy indicator - the Shannon entropy.

\section{Experimental results}

After solving the problems theoretically, we tested the methodology described in the previous sections experimentally. The methods developed for mother wavelet selection were tested while analysing the $2 \mathrm{D}$ surface roughness profile shown in Fig. 3.

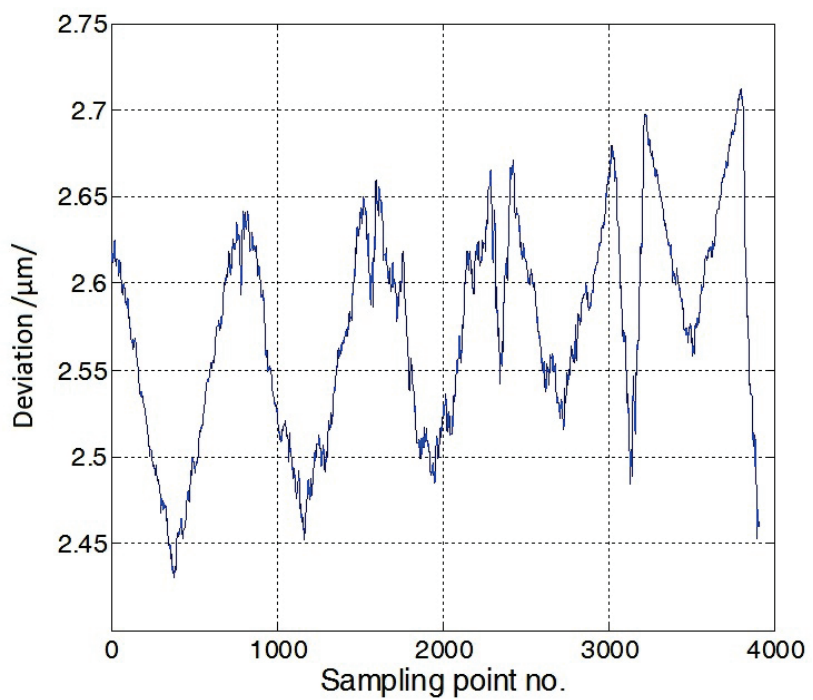

Figure 3 Analysed roughness profile

Table 1 Results of the mother wavelet selection for the methods tested

\begin{tabular}{|l|c|c|c|}
\hline \multirow{2}{*}{ Mother wavelet type } & \multicolumn{3}{|c|}{ Result } \\
\cline { 2 - 4 } & Method 1 & Method 2 & Method 3 \\
\hline Haar & - & 0,943 & - \\
\hline Daubechies-2 & - & 0,939 & - \\
\hline Daubechies-3 & - & 0,931 & + \\
\hline Daubechies-4 & + & 0,918 & + \\
\hline Daubechies-5 & + & 0,900 & + \\
\hline Coiflets-3 & - & 0,861 & - \\
\hline Coiflets-5 & - & 0,740 & - \\
\hline Symlets-4 & - & 0,937 & + \\
\hline Symlets-6 & - & 0,925 & + \\
\hline Biorthogonal 1,5 & + & 0,925 & - \\
\hline Biorthogonal 2,4 & - & 0,926 & + \\
\hline Biorthogonal 4,4 & - & 0,929 & + \\
\hline
\end{tabular}

In the experiment, we tested the Haar, Daubechies, Coiflets, Symlet and biorthogonal wavelets. The calculation results are given in Tab. 1. Method 1 uses the white noise test, Method 2 is based on the crosscorrelation function, and Method 3 requires applying the Shannon entropy.

\section{Optimal decomposition tree}

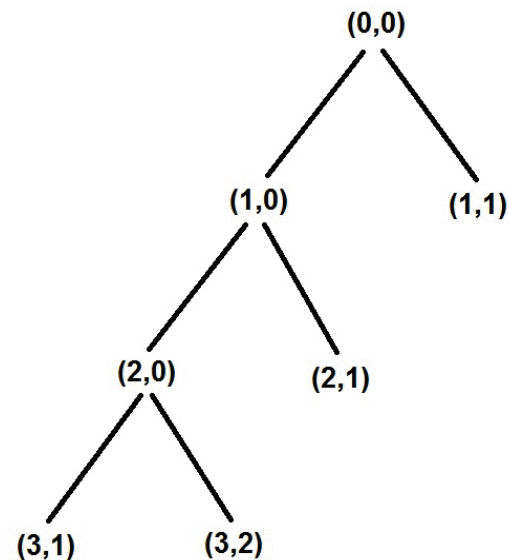

Figure 4 Optimal decomposition tree of the analysed roughness profile (third level of decomposition)

When the result of the white noise testing is positive, i.e. marked with a plus symbol $(+)$, the examined detail is regarded as white noise. A minus sign $(-)$, on the other hand, indicates that the examined wavelet was not selected correctly. The results of the calculations based on the cross-correlation function should be interpreted as follows: the higher the correlation coefficient, the better the selection of the mother wavelet. The results of Method 3 (the Shannon entropy) provide an optimal decomposition tree. It can be assumed that such decomposition has been found $(+)$ if the optimal tree is different from the full binary tree. Fig. 4 illustrates the optimal tree of decomposition of the analysed signal (at the third level).

\section{Conclusion}

The experimental results show that the entropy-based method is the most suitable approach. It is not limited to one level of decomposition and it allows us to find an optimal decomposition tree. The other methods discussed in the paper cannot be used to compute an optimal tree because the decomposition is performed only at one level. Further research is required to carry out an autocorrelation test for a large number of profiles and evaluate the data statistically. It would also be essential to compare results for different segments of the same profile. Further analysis of the cross-correlation function should involve determining the correlation between the original signal and the signal approximated at successive levels of decomposition. While studying the entropy-based methods we should estimate the influence of the mother wavelet on the position of the minimum entropy in a decomposition tree.

\section{Acknowledgement}

This work was supported by the Ministry of Science and Higher Education, Poland (grant No. N R0300 2510).

\section{References}

[1] Sadilek, M. et al. Aspects of using tool axis inclination angle. // Strojniski Vestnik. 57, 9(2011), pp. 681-688. DOI: 10.5545/sv-jme.2010.205 
[2] Hatala, M. et al. Research of the Technological Parameters Importance for Plasma Arc Thermal Cutting. // Applied Mechanics and Materials. 110-116 (2012), pp. 3742-3749.

[3] Čep, R.; Neslušan, M.; Barišič, B. Chip Formation Analysis During Hard Turning. // Strojarstvo. 50, 6(2008), pp. 337345.

[4] Adamczak, S.; Orzechowski, T.; Stańczyk, T. L. The infrared measurement of form deviations of machine parts in motion. // Measurement. 40 (2007); pp. 28-35. DOl: 10.1016/j.measurement.2006.05.004

[5] Adamczak, S.; Miko, E.; Cus, F. A model of surface roughness constitution in the metal cutting process applying tools with defined stereometry. // Strojniski Vestnik. 55 (2009); pp. 45-54.

[6] Adamczak, S.; Bochnia, J.; Kundera, C. Stress and strain measurements in static tensile tests. // Metrology and Measurement Systems. 19, 3(2012), pp. 531-540.

[7] Mathia, T. G. et al. Recent trends in surface metrology. // Wear. 271, 3-4(2011), pp. 494-508.

[8] Pawlus, P. Digitisation of surface topography measurement results. // Measurement. 40, 6(2007), pp. 672-686. DOI: 10.1016/.measurement.2006.07.009

[9] Demircioglu, P.; Durakbasa, M. N. Investigations on machined metal surfaces through the stylus type and optical 3D instruments and their mathematical modeling with the help of statistical techniques. // Measurement. 44, 4(2011), pp. 611-619. DOI: 10.1016/j.measurement.2010.12.001

[10] Durakbasa, M. N. et al. The factors affecting surface roughness measurements of the machined flat and spherical surface structures - The geometry and the precision of the surface. // Measurement, 44, 10(2011), pp, 1986-1999.

[11] Grzesik, W. Influence of tool wear on surface roughness in hard turning using differently shaped ceramic tools. // Wear. 265, 3-4(2008), pp. 327-335.

[12] Zawada-Tomkiewicz, A. Estimation of surface roughness parameter based on machined surface image. // Metrology and Measurement Systems. 17, 3(2010), pp. 493-504. DOl: 10.2478/v10178-010-0041-5

[13] Zhengkai, Zhang; Youyun, Zhang; Yongsheng, Zhu. A new approach to analysis of surface topography. // Precision Engineering. $\quad 34, \quad 4(2010)$, pp. 807-810. DOl: 10.1016/j.precisioneng.2010.05.002

[14] Quinsat, Y.; Tournier, Ch. In situ non-contact measurements of surface roughness. // Precision Engineering. 36, 1(2012), pp. 97-103. DOl: 10.1016/j.precisioneng.2011.07.011

[15] Janecki, D. Edge elimination effect elimination in the recursive implementation of Gaussian filters. // Precision Engineering. 36, 1(2012), pp. 128-136. DOI: 10.1016/j.precisioneng.2011.08.001

[16] Janecki, D. Gaussian filters with profile extrapolation. // Precision Engineering. 35, 4(2011), pp. 602-606. DOI: 10.1016/j.precisioneng.2011.04.003

[17] Janecki, D. A generalized $\mathrm{L}_{2}$-spline filter. // Measurement. 42, 6(2009), pp. 937-943. DOl: 10.1016/j.measurement.2009.01.020

[18] Brillova, K. et al. Spectral analysis of metallic surfaces topography generated by abrasive waterjet. // Tehnicki Vjesnik-Technical Gazette. 19, 1(2012), pp. 1-9.

[19] Matesa, B. et al. The influence of heat treatment by annealing on clad plates residual stresses. // Metalurgija. 50, 4(2011), pp. 227-230.

[20] Stefanic, I. et al. Rapid prototyping of casting cores. // Tehnicki Vjesnik-Technical Gazette. 19, 2(2012), pp. 459464.

[21] Monkova, K. et al. Factor analysis of the abrasive waterjet factors affecting the surface roughness of titanium. Tehnicki Vjesnik-Technical Gazette. 18, 1(2011), pp. 73-77.
[22] Neslusan, M. et al. Deformations after heat treatment and their influence on cutting process. Tehnicki VjesnikTechnical Gazette. 18, 4(2011), pp. 601-608.

[23] Hatala, M.; Čep, R.; Orlovský, I. Testing methods of machinability of materials. // Automobil industry. 5, 3(2009), pp. 52-55.

[24] Reibenschuh, M.; Cus, F.; Zuperl, U. Turning of high quality aluminium alloys with minimum costs. // Tehnicki Vjesnik-Technical Gazette. 18, 3(2011), pp. 363-368.

[25] Glowacz, A. Diagnostics of direct current machine based on analysis of acoustic signals with the use of Symlet wavelet transform and modified classifier based on words. // Eksploatacja i Niezawodnosc - Maintenance and Reliability.16, 1(2014), pp. 554-558

[26] Misiti, M.; Misiti, Y.; Oppenheim, G.; Poggi, J. M. Wavelet Toolbox 4 - User's Guide. The MathWorks, Inc. 2007.

\section{Authors' addresses}

Krzysztof Stępień, M.Sc., Dr.

Wlodzimierz, Makiela, M.Sc., Dr. hab.

Kielce University of Technology,

Faculty of Mechatronics and Machine Design,

al. Tysiąclecia Państwa Polskiego 7,

25-314 Kielce, Poland

E-mail: kstepien@tu.kielce.pl

E-mail: wmakiela@tu.kielce.pl

Full Prof. Antun Stoić, Ph.D.

Full Prof. Ivan Samardžić, Ph.D.

J. J. Strossmayer University of Osijek,

Mechanical Engineering Faculty in Slavonski Brod,

Trg I. B. Mažuranić 2,

35000 Slavonski Brod, Croatia

E-mail: astoic@sfsb.hr

E-mail: isamar@sfsb.hr

Responsible person for English language is prof. M. Laczek, Kielce University of Technology. 